\title{
Özel Yetenekli Çocuklarda Farklılaştırılmış Yazma Becerisi Etkinliklerinin BİLSEM Yönergesiyle Uyumluluğunun Maker Modeline Göre İncelenmesi
}

\section{Examination of Differentiated Writing Skills Activities in Specially Gifted Children with the BILSEM Directive According to the Maker Model} Mehmet Kara, Mazhar Ünal

Yazar Bilgileri

Mehmet Kara

Prof. Dr., Gazi

Üniversitesi, Gazi Eğitim

Fakültesi, Türkçe ve

Sosyal Bilimler Eğitimi,

mehkara@gazi.edu.tr

\section{Mazhar Ünal}

Öğretmen, Dumlupınar

Bilim ve Sanat Merkezi,

mazharunal006@gmail.c om

\section{Makale Bilgileri \\ Anahtar Kelimeler Özel Yetenekli \\ Farklılaştırılmış Eğitim \\ Yazma Becerisi \\ Bilim ve Sanat Merkezi \\ Maker Modeli}

\section{Keywords}

Gifted Children

Differentiated Education

Writing Skills

Science and Art Centres

Maker Model

\section{Makale Geçmişi}

Geliş: 14.05.2020

Düzeltme: 02.01.2021

Kabul: 07.01.2021

\section{ÖZ}

1970’li yıllarda eğitim öğretimde bireyselleştirilmiş eğitim kavramının ortaya çımasıyla, öğrencilerin farklı öğrenme profillerinin olduğu anlaşılmıştır. Dolayısıyla da öğrencilerin sahip oldukları vasıflar (hazırbulunuşlukları, öğrenme hızı, stili, gereksinimleri ve ilgi alanları, yetenek ve beceri seviyeleri gibi) belirlenerek onların seviyelerine uygun öğrenme yaşantılarının düzenlenmesi gerektiği anlayışı ortaya çıkmıştır. Genellikle, bir disiplin alanının temel kavram, anlayış ve becerileri, öğrenciden öğrenciye değişmez; değişmesi gereken şey öğrencinin bu kavramlar, anlayışlar ve beceriler ile kendi gelişim seviyesine uygun zorlukta çalışmasını sağlayabilecek bir destek sistemidir. Görevlerin öğrenci için zor olduğunda bıkkınlık ve kızgınlığa, kolay olduğunda ise tembellik ve ilgisizliğe neden olduğu bilinmektedir. Öğretmen, öğrenciye "yakınsak gelişim alanı" çerçevesinde bir görev verdiğinde ve sonra görevi başarılı bir şekilde tamamlaması için ona rehberlik edip desteklendiğinde öğrencinin bağımsız bir şekilde görev yapabilme gelişim alanı genişleyecektir. Özellikle de özel yetenekli öğrencilerin akranlarından ayrıldığı öğrenme stilleri, öğrenme alanları ve tutumları bilinmektedir. Bu sebeple ders içeriklerinde her öğrencinin öğrenme stiline uygun farklılaştırılmış etkinlikler hazırlanmalıdır. Bu araştırmada Türkiye'de özel yetenekli öğrenciler için hazırlanan yazma çalışmalarının nasıl farklılaştırıldığının Marker modeline göre tespit edilmesi amaçlanmaktadır. Bu amaç doğrultusunda Bilim ve Sanat Merkezlerinde kullanılan Türkçe Etkinlik Kitabında yer alan yazma çalışmaları, Maker Modeline göre süreç, ürün, içerik ve ortam farklılaştırılma durumları açısından incelenmiştir.

\section{ABSTRACT}

With the emergence of the concept of individualized education in the 1970s, we understood that students had different learning profiles. Therefore, the understanding that the learning experiences appropriate for students level should be arranged by determining their qualifications (like readiness, the speed of learning, style of learning, needs and interests, and ability and skills) has ensued. Generally, the basic concepts, understanding, and skills of one discipline don't change from students to students; a support system that will enable the student to work with these concepts, insight, and skills at a difficulty appropriate to his or her level of development needs to change. It is known that difficult tasks for students cause frustration and anger, and the easiest tasks cause laziness and indifference. The development area of the student's independence will expand when the teacher gives the student a task within the framework of "zone of proximal development" and then guides and support her or him to complete the task successfully. Especially, gifted students with their learning styles, learning areas, and attitudes differ from their peers. For this reason, differentiated activities should be prepared in the course contents according to the learning style of each student. According to Maker Model, this study aims to determine how the writing activities prepared for gifted students in Turkey differentiate. For this purpose, according to the Maker Model, we examined the writing activities in the Turkish Activity Textbook used in Science and Art Centres (BILSEM) in terms of process, product, content, and environment differentiation.

Makale Türü Araştırma

Önerilen Atıf $\quad$ Kara, M. \& Ünal, M. (2021). Özel yetenekli çocuklarda farklılaştırılmış yazma becerisi etkinliklerinin Bi்LSEM Yönergesiyle uyumluluğunun Maker modeline göre incelenmesi. TEBD, 19(1), 75-96. https://doi.org/10.37217/tebd.736985 


\section{Giriş}

Öğrencilerin birbirinden farklı gereksinimleri vardır. Özellikle de özel yetenekli öğrencilerin öğrenme stilleri, öğrenme alanları ve tutumları bilinmektedir. Bu sebeple özel yetenekli öğrenciler için ders içeriklerinde öğrenme stiline uygun farklılaştırılmış etkinlikler hazırlanmalıdır. $\mathrm{Bu}$ farklılaştırılmış etkinliklerin de belli özelliklere göre sınıflandırılması ve geliştirilmesi gerekmektedir. Türkiye'de temel eğitimden ilk ve orta eğitime kadar devam eden süreçte öğrenciler için etkinliklerin içeriği, etkinlik süreci ve etkinliklerle ilgili ölçme araçları öğrenciden öğrenciye farklılık göstermeyecek şekilde ve onların öğrenme alanları da dikkate alınmadan tüm öğrencilere aynı şekilde sunulmaktadır. Ayrıca bu eğitimdeki öğretim programları öğrencilerin bireysel farklılıklarını dikkate almamakta ve her öğrenci aynı seviyede kabul edilmektedir. Her bireyin gelişim özelliği farklı olduğu düşünüldüğünde farklılaştırılmış eğitim stratejisine ihtiyaç olduğu anlaşılacaktır.

Tomlinson'a (2014) göre farklılaştırılmış eğitim; öğrencilerin programda ifade edilen kazanımlara ulaşmalarını sağlamak amacıyla çeşitli yöntem ve tekniklerin kullanıldığı, öğrencilerin becerilerini sergileyebileceği seçimlerin yer aldığı öğrenme yaşantısıdır. Bu öğrenme yaşantısı:

- Farklılaştırılmış eğitimde öğretmenler, müfredat konularını daha önceden belirlenmiş sırasıyla değil de öğrencilerin bulundukları öğrenme seviyesinden hareketle planlarlar. $\mathrm{Bu}$ yüzden farklılaştırılmış eğitimde planlar, eğitim öğretimin başında ve uzun vadeli hazırlanmazlar, öğrencilerin gereksinimlerine göre şekillendirilirler.

- Farklılaştırılmış eğitimde zamanın kullanımı da esnektir ve öğrencilerin gelişim seviyesine göre planlama yapılır.

- Bu şekilde yapılan eğitimlerde, değerlendirme de eğitim sürecinin sadece sonunda değildir, süreklidir. Değerlendirmedeki amaç bir sonraki öğrenme yaşantısının nasıl gerçekleştirileceğini ön plana çıkartmayı amaçlamaktadır.

- $\mathrm{Bu}$ amaç sayesinde öğrencilerin tamamına hitap eden bir öğrenme yaşantısı sunulacaktır ve her öğrenci etkinlik sürecinde etkin bir rol alacaktır.

- Farklılaştırılmış eğitimde öğretmen içerikte öğrenme-öğretme sürecinde, üründe ve ölçme değerlendirmede öğrenci gereksinimlerine göre çeşitlendirmeye gitmelidir.

Farklılaştırılmış eğitim sürecinde, zenginleştirilmiş etkinlikler ile öğrencilere uygulanan öğrenme yaşantılarının çeşitlendirilmesi anlaşılmaktadır. Zenginleştirmeler genellikle öğrenci ihtiyaçlarına göre belirlenmektedir. Öğrenci ihtiyaçlarına ve ilgilerine uygun etkinlik materyalleri, proje ve kapsamlı çalışmalar, deneyler, gözlem araçları, bilişim teknolojileri, eğitsel oyunlar vb. yoluyla yapılabilmektedir. Zenginleştirme sırasında konunun kapsamı genişletilerek ilgili kavram 
alanında soyutlamaya gidilebilir. Bu sayede etkinliklerin zorluk derecesi artırılarak öğrencide öğrenmeye yönelik artan bir talep oluşması sağlanacaktır.

Türkçe derslerinde farklılaştırılmış öğrenme yaşantılarının içerisine yazma becerilerini de dâhil etmek gerekir; çünkü bir konu verilip sınıfın bu konu hakkında ve belli bir türde yazı yazmasını istemek öğrencilerin bireysel farklılıklarını göz ardı etmek olacaktır. Yazma çalışmalarında belli bir konu da verilmiş olsa bu konuyu dile getirmede öğrencilere farklı yazma süreçleri sunulmalıdır. Yazma süreçlerini farklılaştırmak için öğrencilerin hazır bulunuşlukları, derse ilgileri, öğrenme stilleri ve kültürlerini bilmek ve bu özelliklere göre de öğrencileri gruplandırmak gerekecektir.

Türkiye'de özel yetenekli öğrenciler, örgün öğretim süreçlerine ek olarak planlanan Bilim ve Sanat Merkezlerinde eğitimlerine devam ederler. Burada öğrenciler için hazırlanan etkinlikler öğrencilerin var olan potansiyellerini en ileri seviyede kullanarak gelişim sağlamaya yönelik şekilde gerçekleştirilmektedir. Bu amaçla özel yetenekli öğrencilerin eğitim gördüğü Bilim ve Sanat Merkezlerine öğrenciler; görsel yetenekler, müzik yeteneği ve genel zihinsel beceriler alanlarından katılım sağlamaktadır. Bu öğrenciler öğrenme stillerine göre sınıflandırıldıkları için hazırlanan ders içi etkinliklerde; etkinlik içeriğinde, etkinlik sürecinde ve ürün çıktısında farklılaştırmaya ihtiyaç vardır. Bu sebeple öğrencilerin hazır bulunuşlukları, ilgileri ve öğrenme profilleri göz ardı edilmemelidir. Dil becerilerinden yazma becerisini geliştirmeye yönelik etkinlikler yukarıda bahsedildiği gibi öğrencilerin öğrenme stillerine hitap edecek nitelikte olmalıdır. Özel yetenekli öğrenciler için hazırlanan yazma çalışmaları da bu üç sınıflandırmaya göre farklılaştırılmakta ve etkinlikler yoluyla aynı kazanımlara ulaşmak için de zenginleştirmeye ve disiplinler arası iş birliğine gidilmektedir. Bu etkinliklerin değerlendirilmesinde de farklılaştırılmış etkinlikleri ölçebilecek nitelikte ölçeklerin geliştirilmesi gereklidir.

"Farklılaştırılmış eğitim, zenginleştirilmiş etkinlik, yazma becerisi, BİLSEM, yaratıcı yazma" anahtar kelimeleriyle YÖK (Yükseköğretim Kurulu) Ulusal Tez Merkezi, YÖK Akademik, Ulusal Akademik Ağ ve Bilgi Merkezi (ULAKBİM) ve Dergipark veri tabanlarında yapılan taramada özel yetenekliler konusunda anne baba görüşleri, dikkat eksikliği ve liderlik becerileri konuları tespit edilmiştir. $\mathrm{Bu}$ çalışmalar (Çavuşoğlu ve Semerci, 2015; Demirçelik, Karacabey ve Cenan, 2017) şeklindedir. Özel yetenekli çocukların farklılaştırılmış yazma çalışmalarıyla ilgili bir çalışma tespit edilememiştir. Özel yetenekli öğrenciler için hazırlanan yazma çalışmalarının nasıl farklılaştırıldığının tespit edilmesi, Türkiye' de henüz başlangıç aşamasında olan bu alanın gelişmesi çalışmalarına katkı sağlayacaktır. Bu çalışmanın amacı Türkiye'de özel yetenekli öğrenciler için hazırlanan yazma çalışmalarının nasıl farklılaştırıldığının tespit edilmesidir. Bunun için Bilim ve Sanat Merkezlerinde yürütülen etkinlik içeriklerinin Bilim ve Sanat Merkezleri Yönergesiyle uyumluluğu karşılaştırılmıştır. 
$\mathrm{Bu}$ amaç doğrultusunda araştırma metodolojisinde öncelikle Maker Modeli'ndeki farklılaştırma kavramlarının kavramsal çerçevesi verilecektir. Daha sonra Maker Modeli'ne bağlı olarak tespit edilen yöntem, bulgulara, tartışma ve sonuç bölümlerine yer verilecektir.

\section{Maker Modeline Göre Farklılaştırma}

Müfredat modelleri yeni modellerin geliştirilmesinin yanında uygulamada olan modellerin farklılaştırılmasına rehberlik ederler. Müfredat farklılaştırma stratejisi, üstün yetenekli öğrencilerin eğitimlerinde en çok kullanılan öğretim stratejisidir (Sak, 2017). Farklılaştırma sürecinde genel müfredatın bazı yerleri atılır, eğitimde hızlandırma olarak gerçekleşir; kimi zaman da genel müfredata ek olarak yeni kazanımlar eklenir. Maker'e (1982) göre de üstün zekâlı öğrencilerin eğitimlerinde müfredat ögeleri hem nicel olarak hem de nitel olarak farklılaştırılmalıdır. Bu modelde genel müfredat ögelerinde içerik, süreç, ürün ve öğrenme ortamı olmak üzere dört ana boyutta farklılaştırma yer alır. Bu yapılar da kendi içlerinde soyutluk, karmaşıklık, çeşitlilik, organizasyon, seçkin kişilerin yaşamı; araştırma yöntemleri, ileri düzey düşünme, açık uçluluk, keşifçi öğrenme, akıl yürütme, çeşitlilik, öğretimin hızı; gerçek yaşam problemleri, gerçek alıcı kitle, değerlendirme, sentezleme, çeşitlilik; öğrenen merkezli-öğreten merkezli, kabul edicilik-yargılayıcılık, değişken gruplama-benzer gruplama, bağımsızlık-bağımlılık, karmaşıklık-basitlik, açıklık-kapalılık alt boyutlara ayrılmıştır.

Maker (1982), üstün yetenekli öğrencilerde farklılaştırılmış bir öğretimin verilmesini önermiş ve bu öğretimin içerik alanında nasıl yapılabileceğini belirtmiş ve içerikteki farklılaştırmayı aşă̆ıdaki gibi açıklamıştır:

İçerik;

“a) Soyut, karmaşık ve normal müfredattan farklı olan içerik konularını kapsar.

b) Bireysel ihtiyaçlara ve ilgilere daha fazla hitap eder.

c) Disiplinler arası etkileşime önem verir.

ç) Gerçek hayatta karşılaşılan problemlerin incelenmesine teşvik eder.

d) Çeşitli konularla öğrencilerin duyuşsal özelliklerinin desteklenmesini teşvik eder."

Maker (1982), üstün yetenekli öğrencilerde farklılaştırılmış öğretimin süreç alanında nasıl yapılabileceğini belirtmiş ve süreçteki farklılaştırmayı aşağıdaki gibi açıklamıştır:

Süreç;

“a) Üst düzey bilimsel düşünme süreçlerini geliştirir.

b) Keş̧fetme ve deneyime dayalı öğrenme için firsatlar sağlar.

c) Açık-uçlu problemlere çözümler sağlar.

ç) Bağımsız araştırmalar için araştırma becerilerini öğretir. 
d) Farklı öğrenme stillerine hitap etmek için çeşitli öğrenme stratejilerini kullanır.

e) Küçük grup faaliyetlerine imkân sağlar."

Maker (1982), üstün yetenekli öğrencilerde farklılaştırılmış öğretimin ürün alanında nasıl yapılabileceğini belirtmiş ve üründeki farklılaştırmayı aşağıdaki gibi açıklamıştır:

Ürün;

“a) Gerçek dünya sorunları içerir.

b) Gerçek yaşama dayal ö̆grenmeye değer verir.

c) Yaratıcılı̆̆ı ortaya koyma imkânı sunar.

ç) Geleneksel ödev mantığının ötesinde farklı şekillerde sunum yapılmasını cesaretlendirir."

Maker (1982), üstün yetenekli öğrencilerde farklılaştırılmış öğretimin öğrenme ortamında nasıl yapılabileceğini belirtmiş ve üründeki farklılaştırmayı aşağıdaki gibi açıklamıştır:

Öğrenme Ortamı;

“a) Destekleyici ve öğrenci merkezli bir ortam sağlar.

b) Risk almayı destekler.

c) Teşvik edici bir fiziksel ortam sağlar.

ç) Okul dışı öğrenme deneyimleri sağlar (geziler, toplumsal projeler vb.).

d) Yükseköğretim kurumlarn ile işbirliğini destekler."

\section{Araştırmanın Amacı}

Bu araştırmada Türkiye'de özel yetenekli öğrenciler için hazırlanan yazma çalışmalarının nasıl farklılaştırıldığının Marker modeline göre tespit edilmesi amaçlanmaktadır. Bu amaç doğrultusunda ayrıntılı bilgilere ulaşmak için aşağıdaki sorular tasarlanmıştır:

1. Bilim ve Sanat Merkezlerinde kullanılan Türkçe Etkinlik Kitabında yer alan yazma çalışmalarının Maker Modeline göre süreç, ürün, içerik ve ortam açlarından farklılaştırma durumları nedir?

2. Türkçe Etkinlik Kitabında yer alan yazma çalışmalarının Bilim ve Sanat Merkezleri Yönergesiyle uygunluk durumu nedir?

\section{Yöntem}

Çalışmada nitel araştırma yöntemi kullanılmıştır. Araştırma verileri, nitel araştırma yöntemlerinden doküman incelemesi yoluyla toplanmıştır. Doküman incelemesi, araştırılması hedeflenen olgu ya da olgular hakkında bilgi içeren yazılı materyallerin analizini kapsamaktadır. Doküman incelemesi, bir araştırma problemi hakkında belirli zaman dilimi içerisinde üretilen dokümanlar veya ilgili konuda birden fazla kaynak tarafından ve değişik aralıklarla üretilmiş 
dokümanların geniş bir zaman dilimine dayalı analizini olanaklı kılmaktadır ve eğitim ile ilgili bir araştırmada ders kitapları ve öğretim programları doküman incelemesinde veri kaynağı olarak kullanılabilir (Yıldırım ve Şimşek, 2008). Araştırmada farklılaştııılmış yazma çalışmalarının toplanması amaçlandığından bu yöntem tercih edilmiştir.

Doküman incelemesi yapılan bu araştırmada beş aşama izlenmiştir: Dokümanlara ulaşma, dokümanların kontrol edilmesi, dokümanların anlaşılması, verilerin analiz edilmesi ve çalışmanın amacı doğrultusunda elde edilen verilerin kullanılması yoluna gidilmiştir. Ayrıca çalışmanın amacına göre verilerin işlenmesi, bulguların tanımlanması, bulguların yorumlanması aşamalarını kapsayan betimsel analiz tekniği kullanılmıştır (Yıldırım ve Şimşek, 2008).

Araştırmanın bazı verilerine ulaşmak için, YÖK Ulusal Tez Merkezi, YÖK Akademik, ULAKBIM ve Dergipark veri tabanlarında ayrıntılı tarama gerçekleştirilmiştir. Konu başlıklarında anahtar kelime olarak "farklılaştırılmış eğitim" ve "zenginleştirilmiş etkinlik" başlıkları taranmıştır. Bunlara ek olarak dizin terimlerine ve tez adına "yazma becerisi" anahtar kelimesi yazılarak tarama tamamlanmıştır.

Araştırmanın çalışma grubunu Bilim ve Sanat Merkezlerinde kullanılan Türkçe Etkinlik Kitabı'ndaki yazma becerisi etkinlikleri, Bilim ve Sanat Merkezi Türkçe Öğretim Programı ve Millî Eğitim Bakanlığı Bilim ve Sanat Merkezleri Yönergesi oluşturmuştur.

Çalışmanın amacı doğrultusunda Bilim ve Sanat Merkezlerinde yazma becerisi etkinliklerine, Bilim ve Sanat Merkezi Türkçe Öğretim Programına, Bilim ve Sanat Merkezleri Yönergesine yer verilmiştir.

\section{Bulgular}

Özel yetenekli öğrenciler, eğitim hayatları boyunca sahip oldukları bilişsel özelliklere uygun eğitim-öğretim fırsatlarına ve ortamlarına gereksinim duyarlar. Türkçe derslerinde müfredatın ve dolayısıyla etkinliklerin farklılaştırılması aracılığıyla özellikle yazma çalışmalarında bu tip öğrencilerin bireysel farklılıklarının gözle görülür bir şekilde öne çıktı̆̆ı görülmektedir. Bu farklılıkları ortaya çıkartacak etkinlik örneklerin olması, öğrencilerin daha erken ve kolay fark edilip onların bireysel ilerlemesini destekleyecektir. Bu destekleme işi de ders kitaplarındaki zenginleştirilmiş etkinlikler aracılı̆̆ıyla verilmelidir. Bu ekinliklerin zenginleştirilmesi, hem ders programıla hem de Bilim ve Sanat Merkezleri Yönergesiyle sağlanmaktadır.

Maker Modeli' ne göre tespit edilen bulgular aşağıdaki gibi sıralanmıştır:

1. Maker Modeline Göre İçeriğin Farklılaştırılması Açısından Yazma Becerisi Etkinliklerinin Bilim ve Sanat Merkezleri Yönergesiyle Uyumluluğu

Özel yetenekleri geliştirmeye yönelik programlar, disiplinler ve disiplinler arası yaklaşımlar 
dikkate alınarak herhangi bir disiplinde derinlemesine veya kapsamı genişletilerek ileri düzeyde bilgi, beceri ve davranış kazandırmak amacıyla hazırlanır (Milli Eğitim Bakanlığı [MEB], 2015). Bu amaç doğrultusunda Bilim ve Sanat Merkezlerine devam eden öğrenciler için öğrenme stillerine göre gruplama yapmak mümkündür. Yapılan bu gruplandırmaya uygun olacak şekilde öğrencilere farklı tema-konu veya metin türlerinde yazma görevleri verilebilmektedir. Bilim ve Sanat Merkezleri Türkçe Etkinlik Kitabında, öğretmenin farklı öyküleyici metin türleri kullanabileceği (MEB, 2017b, s. 142), öğrencilerin çalışma yapacakları bir tür seçmelerine imkân tanınmaktadır (MEB, 2017b, s. 150). Bu sayede öğrenciler istedikleri türde ve konuda kendi öğrenme stillerine uygun yazma çalışmaları yapabileceklerdir. Yazma konularında veya temalarında içeriği oluştururken ileri düzeyde ve soyut konuları ele almaya fırsatları da verilmektedir.

Türkçe Etkinlik Kitabındaki;

27. Etkinlikte, ön hazırlık olarak öğrencilerden karikatür incelemeleri ve karikatür örnekleri bulmaları istenir. Bu aşama etkinlik başlangıcında yaptırılabileceği gibi bir önceki derste görev olarak da verilebilir. Karikatürlerin yazılı ve yazısız olmasının anlatılmak istenene etkisi sorgulatılır. Konuşma balonları olmayan karikatürlere konuşma balonları eklenerek ya da konuşma balonlarının içindeki yazılar silinerek boşaltılmış karikatürler öğrencilere dağıtılır. Öğrencilerden konuşma balonlarının doldurulması istenerek görsele uygun ve anlamlı olarak doldurup doldurulmadıkları kontrol edilir. Konuşma balonlarını doldurdukları karikatürlerinden hareketle mizahi özellikleri ağır basan kısa bir öyküleyici metin oluşturmaları istenir (MEB, 2017b, s. 287).

Öğrencilerden, hikâyelerini yazarken metinlerarasılık yapmaları istenmiştir (MEB, 2017b, s. 287). Öğrencilerin yazılı ürünlerinde metinlerarasılık yapmaları soyut, karmaşık ve normal müfredattan farklı olan içerik konularını kapsamaktadır. Ayrıca grup seviyesinin üzerinde olan öğrencilerin kendi ürünlerini oluşturmaları desteklenecektir (MEB, 2017b, s. 287). Bu sayede bireysel hızda ilerleme de desteklenmiş olacaktır.

30. Etkinlikte, çektikleri fotoğraflardan yola çıkarak hikâyelerini yazmaları istenir. Hikâyelerini yazarken metinlerarasılık yapmaları sağlanır. Okuduklarından, dinledikleri/ izlediklerinden yaptıkları fişlemeleri kullanabilecekleri belirtilir (MEB, 2017b, s. 293).

32. Etkinlikte, öğrencilere algoritma örnekleri sunularak birlikte incelenir. Daha sonra öğrencilerden kendi belirleyecekleri bir konu ile ilgili akış diyagramı hazırlamaları istenir. Hazırlanan diyagramlar birlikte değerlendirilir. Olay örgüsü oluşturacak nitelikte yeni bir algoritma oluşturmaları istenerek tıpkı algoritmalarda olduğu gibi evet ya da hayır cevaplarıyla okuyucuyu yönlendirecekleri bir hikâye yazmaları sağlanır. Örneğin: Çam ağacının kesilmesini istiyorsanız 6 . cümleye, çam ağacının kesilmemesini istiyorsanız 11. cümleye gidiniz. (Burada cümle olarak verilen 
geçişler sayfa olarak da verilebilir.) Öğrencilerin, birbirlerinin hikâyelerini okuyarak eleştirmeleri sağlanır. Yazılan hikâyeler, bilgisayarda algoritmalara uygun olarak düzenlenir (MEB, 2017b, s. 297).

34. Etkinlikte, etkinlik ön hazırlık gerektirmektedir. Öğretmen kullanılabilecek yöntemler hakkında bilgi sahibi olmalıdır. Öğretmen öğrencilerden bir öykü yazmalarını ister. Daha sonra öğretmen dijital öykü örnekleri göstererek öğrencileri bilgilendirir. Öğrenciler öyküyü yazdıktan sonra bilgisayarda öyküye uygun görseller (kişi, yer, olay, zaman, duygu vb.) ararlar. Bulunan görseller Power Point, Imovie, Animoto, Slide.ly, Powtoon, Storyjumper gibi programlar aracılığıyla birleştirilir. Birleştirilen görseller öğrencilerin yazdıkları öyküyü tamamlayıcı bir nitelikte olmalıdır. Birleştirilen görsellere uygun olarak öğrenci tarafından ses kaydı yapılır (MEB, 2017b, s. 300).

Bu hedef doğrultusunda Bilim ve Sanat Merkezleri Türkçe Etkinlik Kitabında, Programdaki; “4.1.13 Öyküleyici metin türleri arasında metinlerarasılık yapar." (MEB, 2017b, s. 293) ve "4.1.7 Öyküleyici metinlerinde metaforlardan yararlanır." (MEB, 2017b, s. 297-300) şeklindeki kazanımlarıyla ilgili etkinliklere yer verilmiştir.

52. Etkinlikte, öğretmen, öğrencilere kaç kişinin apartmanda oturduğunu sorar. Apartmanda veya sitelerde yaşayan insanların birbirlerini ne kadar tanıdıkları sorulur. Özellikle yalnız yaşayan yaşlılarla ilgili medyada olumsuz haberlere rastlayıp rastlamadıkları sorulur. (Öğretmen, öğrencilerin bu konuda yorum yapmama ihtimaline karşı ön hazırlık yapmış olmalıdır.)

Günümüzde özellikle büyük şehirlerde yaşayan insanların yalnızlaşmaya başlamalarının sebepleri balık kılçı̆̆ı yöntemiyle analiz edilir. Nedenleri tespit edilecek problemin başlığı diyagramın baş kısmına yazılır. Daha sonra balığın omurgasına 45 derecelik açıyla oklar çizilir ve okların üzerine ana nedenler yazılır. Son olarak ana nedene de oklar çizilerek bu nedenlerin alt nedenleri yazılır. Grup çalışması şeklinde yaptırılarak grupla işbirliği de geliştirilebilir. Daha sonra kendilerine ait bir sorun için balık kılçığı yöntemini kullanarak sorunun nedenlerini analiz etmeleri istenir. Konuyla ilgili araştırma yapmalarına fırsat tanınır. Araştırma verilerini fişlemeleri sağlanır (MEB, 2017b, s. 163).

Türkçe Etkinlik Kitabında, gerçek hayatta karşılaşılan problemlerin incelenmesini teşvik eden etkinlikler de yer almıştır (MEB, 2017b, s. 163).

57. Etkinlikte, öğretmen, öğrencilerin önbilgilerini görebilmek için derse sorular sorarak başlar. En sevdikleri fablı, neden sevdiklerini, fabllardaki karakterlerin kimler/neler olduğunu, fabllardaki değer yargılarını, fablların diğer metin türlerinden farkını vb. sorarak öğrencilerden geri bildirim alır. Öğrencilerin ilgileri konuya yoğunlaştıktan sonra bir fabl yazacaklarını, yazacakları fablın karakterlerini ve konusunu kura ile belirleyeceklerini, arkasından fablı resmedip yapboz hâline getireceklerini söyler.

Öğretmen, yapacakları kura ile herkesin iki adet hayvan kartı ve bir adet değer kartı seçerek, fabllarındaki karakterler ve konuyu bu kartlar çerçevesinde oluşturacağını mekân ve zaman 
kurgusunda ise serbest olduklarını ifade eder. (Kültürel değerlerin yazılacağı kartlar için kadirşinaslık, vefa, kanaat, ... ile hemhâl olmak, tevazu, irade vb. kelimeler seçilerek kelime öğretimi de yapılabilir.) Daha sonra gerekli açıklamalar yapılarak öğrencilere metinlerini yazmaları için süre verilir (MEB, 2017b, s. 175).

Çeşitli konularda öğrencilerin duyuşsal özelliklerini destekleyen kültürel değerleri de yazdıkları metinlerde kullanmaları beklenmektedir (MEB, 2017b, s. 175). Böylelikle öğrencilerin duyuşsal özellikleri desteklenmektedir.

“Etkinlik içeriklerinde alan becerileri gruptan farklı olan öğrenciler için öneri mahiyetinde ek aşamalar bulunmaktadır. Bu aşamaların uygulanması ile ilgili süreç öğretmenin kontrolündedir. Öğrencilerin hazırbulunuşluğuna, farklı ilgi ve yetenek alanlarına göre etkinliklere eklemeler yapmanız faydalı olacaktır" (MEB, 2017b, s. 2).

Etkinlik içeriklerinde alan becerileri gruptan farklı olan öğrenciler için öneri mahiyetinde bu ek aşamaların uygulanması ile ilgili sürecin öğretmenin kontrolünde olduğu belirtilmiştir. Öğrencilerin hazır bulunuşluğuna, farklı ilgi ve yetenek alanlarına göre etkinliklere eklemeler yapmaya olanak tanınmıştır (MEB, 2017b, s. 2) ve tüm yazma etkinliklerinde disiplinlerarası iş birliğine yer verilmiştir.

Öğretim programının içeriği ile yazma becerilerinde verilen yapılar karşılaştırıldı ğında resimlerden, şekillerden yararlanıldığı, soyutluk ilkesi dikkate alındığı ve daha az veri düzeyinde bilgiye yer verildiği, yazma becerilerinde karmaşıklık kavramının yer aldığı, genelleme yapmaya imkân tanındığı, birden fazla kavram arasında ilişki kurulduğu, bağımsız çalışmayı teşvik ettiği, yazma becerileri açısından çeşitlilik sunduğu anlaşılmıştır ve Bilim ve Sanat Merkezleri Yönergesiyle de uyumlu olduğu tespit edilmiştir.

\section{Maker Modeline Göre Sürecin Farklılaştırılması Açısından Yazma Becerisi Etkinliklerinin Bilim} ve Sanat Merkezleri Yönergesiyle Uyumluluğu

Bilim ve Sanat Merkezlerine devam eden öğrenciler için etkinliklerde belirtilen süreler zenginleştirmelere, etkinlikte uygulanacak aşamalara ve öğretmenlerin yapacakları eklemelere göre artırılabilmekte/azaltılabilmektedir (MEB, 2017b, s. 2). Bu sayede Bilim ve Sanat Merkezlerine devam eden öğrenciler için öğrencilerin bulundukları seviyelere uygun süreç içerisinde farklılaştırmaya yönelik açılamalara yer verilmiştir.

Uygulanacak programların süreleri, öğrencilerin performansları doğrultusunda şekillenmektedir (MEB, 2015). Bu sayede yazma çalışmalarında gruplama, hızı farklılaştırma ve desteği farklılaştırmaya imkân tanınmıştır. 
Türkçe Etkinlik Kitabındaki;

31. Etkinlikte, öğretmen öğrencilerin noktalama işaretleri konusundaki ilgi ve bilgilerini ölçmeye yönelik sorular sorarak etkinliği başlatır. Noktalama işaretlerinin önemi vurgulanır. Noktalama işaretlerinin olmadığı bir dünyada hayatımızdaki değiş̧ikliklerin neler olabileceği üzerine beyin fırtınası yapılır. Aşağıdaki metin okunur ve üzerinde tartışılır.

Noktalama İşaretlerini Kaybeden İnsan:

İnsanoğlu bir gün virgülü kaybetti, söyledikleri birbirine karıştı. Noktayı kaybetti: Düşünceleri uzayıp gitti, ayıramadı onları.

Ünlem işaretini kaybetti bir gün de: Sevincini, öfkesini, tüm duyguların yitirdi. Soru işaretini kaybetti bir başka gün: Soru sormayı unuttu o zaman.

İki noktayı kaybetti bir başka gün: Hiçbir açıklama yapamadı.

Yaşamının sonuna geldiğinde elinde yalnızca tırnak işareti kalmıştı "İçinde de başkalarının düşüncesi vardı yalnızca.

Öğrenciler noktalama işaretlerinden birini seçerler. Seçtikleri noktalama işaretini bir kahraman yerine koyarak işaretin maceralarını öyküleyici metin şeklinde yazarlar. Anlatım görseller ile zenginleştirilir. Metinlerin canlandırması yapılır. Etkinliğin zenginleştirilmesine bağlı olarak süre eklenebilir (MEB, 2017b, s. 295).

Öğrencilerin üst düzey bilimsel düşünme süreçlerini geliştirmelerine olanak sağlayan yazma becerisi etkinliklerine yer verilmiştir (MEB, 2017b, s. 287, 295, 300). Bu sayede öğrencilerin uygulama basamağının üstüne çıkabilmelerine fırsat sağlayan süreç sağlanmıştır.

36. Etkinlikte, öğretmen, önceden planlayacağı ve öğrencilerin farklı bakış açılarına sahip olduğunu bildiği bir konuda görüşlerini sorarak etkinliğe giriş yapar. Bir konuda kaç farklı bakış açısı olabileceği üzerinden kısa bir tartışma başlatılır. Ferit Edgü'nün "Yazmak Eylemi” kitabından ve bu kitapta, bir olayın 101 farklı bakış açısıyla tekrar yazıldığından bahsedilerek EK-1'de verilen önsöz okutulur. Ardından öğrencilere süre verilerek bir olayı canlandırmaları istenir. Örneğin; bir kız, bir erkek iki kardeşin annelerinin yanında tartışması istenir. Öğretmen mikro öğretim için canlandırmayı video kaydına alır. Canlandırmanın ardından öğrencilerin bu olayı üç ayrı kişinin ağzından, (olay ve kişi sayısı gruptaki öğrenci sayısına göre değiştirilebilir) onların bakış açısı ile yazmaları istenir. Metinlerini yazarken kişilerin o anki psikolojik durumları, öncesinde yaşadıkları ya da sonrasında hissettikleri vb. ayrıntılara değinmeleri ve bu metni bilgilendirici bir metin niteliğinde yazmaları gerektiği vurgulanır. Örneğin kız kardeşin bakış açısı ile olay nasıl gerçekleşmiştir, erkek kardeşin bakış açısı ile olay nasıl gerçekleşmiştir, olaya şahit olan annenin bakış açısı ile olay nasıl gerçekleşmiştir? Metinler tamamlandıktan sonra okunarak ve dinleyen öğrencilerin kendilerini 
mahkemede bir hâkim gibi düşünmeleri, metin okunduktan sonra hüküm vermeleri ve verdikleri hükmü gerekçeleri ile açıklamaları gerektiği söylenir. Hâkim olarak kararlarını söyleme anları yapılan video kaydına eklenir. En son, video kaydı baştan sona kadar seyrettirilerek hep birlikte haklılık, sayg1, karar verme sorumluluğu, özgürlük, üslup vb. konular üzerine son değerlendirme yapılır.

NOT-1: Bu etkinlikte verilen kitap ve olay örneği tavsiye niteliğindedir. Dilerse öğretmen farklı kitap ve olaylar kullanabilir.

NOT-2: Etkinlik sürecine ve öğrenci performanslarına bağh olarak sürede değişiklik yapılabilir.

(MEB, 2017b, s. 304-305).

Öğrencilerin keşfetme ve deneyime dayalı öğrenmelerini sağlamak için yazdıkları metinleri dramatize etmeleri (MEB, 2017b, s. 164, 304) istenmiştir ve yazılanların deneyimlenmesi amaçlanmıştır.

Destek etkinliklerinden 48 ve 51. etkinlikler ile bireysel yetenek alanındaki 27, 33 ve 46. etkinliklerde ölçme aracı olarak açık uçlu sorulara yer verilmiştir.

Öğrencilerin yazdıkları ürünlerin değerlendirilmesinde açık uçlu sorulardan oluşan ölçekler kullanılmıştır (MEB, 2017b, s. 152, 161, 287, 299, 329). Bu sayede öğrencilerin yazılarını özgürce değerlendirmeleri amaçlanmıştır.

54. Etkinlikte, öğrencilerin kullandıkları iletişim araçlarını kullanım sıklıklarına göre sıralamaları istenir.

Özellikle yazılı iletişim araçları ile ilgili sorular sorularak öğrencilerin bilgiye ulaşma amaçlı olarak kullandıkları yazılı iletişim araçlarına vurgu yapılır. Gazete incelemeleri yapılarak haber metinleri ile bir konuda yazarın güncel bir olayı kişisel olarak ele alıp yorumladığı metinleri (Fıkra) ayırt etmeleri istenir. Fıkra örnekleri incelettirilerek, türün genel özellikleri sezdirilir. Güncel olaylar ile ilgili beyin fırtınası yaptırılarak her öğrencinin bu olaylardan bir tanesini seçmesi sağlanır. Seçilen konuda kısa bir fıkra metni (yaş ve seviyeye bağlı olarak öğrenciye rehberlik edilmesi çok önemlidir) yazmaları istenir. Sınıf panosunda bir köşe oluşturulur. Yazılan metinler birlikte değerlendirilerek sınıf panosuna asılır. Öğrencilere panodaki yazıların her hafta yenileriyle değiştirileceği söylenerek yazma alışkanlığı kazanmalarına destek olunur. Öğrenciler, bilgilendirici metin yazarları ve eserleri ile ilgili araştırma yapmaya yönlendirilir. Elde ettikleri verileri düzenleyerek bilgilendirici metin oluşturmaları ve bu metinleri arkadaşları ile paylaşmaları istenebilir (MEB, 2017b, s. 168).

Öğrencilere yazma alışkanlığı kazandırmak amacıyla bağımsız araştırmalar yapmalarına fırsat veren etkinliklere yer verilmiştir ve bu etkinlikler aracılığıyla fişlerden yararlanabilecekleri belirtilmiştir (MEB, 2017b, s. 168, 305). 
44. Etkinlikte, öğrencilere bir kelime verilerek verilen kelime için bir hikâye yazacakları söylenir. Verilen kelimeden hareketle hikâyede geçecek şahıs kadrosu, yer, zaman gibi unsurları bulmaları istenir. Örneğin; Kelime: Çiçek, Kişi: Çiçekçi kız, Yer: Çiçek Bahçesi, Zaman: Çiçek ayı gibi... Tüm öğrenciler verilen kelimeyle isim bulmaya devam ederler. Fikir üretme süresi uzamaya başlayınca ortaya atılan fikirleri değerlendirip ortak karar vermeleri istenir. Daha sonra öğrencilere atık materyaller verilerek belirledikleri fikirler doğrultusunda grup olarak atık materyallerle isterlerse üç boyutlu bir materyal tasarlayabilecekleri ya da kâğıt üzerinde düzenleme yaparak bir resim oluşturabilecekleri söylenir. Oluşturulan görsele ve seçilen zaman, yer, kişi unsurlarına uygun nitelikte bir hikâye yazmaları istenir. azdıkları hikâye kendi belirledikleri grup sözcüsüne okutulur (MEB, 2017b, s. 144).

47. Etkinlikte, öğrencilerin çalışma yapacakları bir tür seçmeleri sağlanır. Öğrencilere grup çalışması yaptırılarak belirlenmiş metin türünde yazı çalışması yaptırılır. Öğrencilerin metin yazmaya dönüşümlü olarak devam etmesi sağlanır. (Dönüşüm bölüm, cümle sayısı gibi kriterlere göre belirlenebilir.) Birbirlerinin yazdıklarına metnin bütünlüğünü bozmadan eklemeler yapmaları sağlanır. Oluşturulan metin gruptaki öğrenci sayısına bağlı olarak belli bölümlerden kesilir. Kesilen bölümler öğrencilere rastgele dağıtılır. Her öğrenci kendisine verilen bölümü tamamlar. Oluşturulan metinleri dil-anlatım ve imla-noktalama yönüyle de değerlendirmeleri sağlanır (MEB, 2017b, s. 150).

51. Etkinlikte, öğrencilere, karikatürde neler gördükleri ve karikatürde anlatılmak istenenlerin neler olduğu sorulur; öğrencilerin düşüncelerini belirtmeleri sağlanır. Karikatürden hareketle düşüncelerini aktaracakları konu-amaç-tür özelliklerine uygun bir metin taslağı hazırlamaları istenir. Hazırlanan taslaklar grupla birlikte değerlendirilerek, taslağın uygunluğu sorgulatılır. Gerekiyorsa ekleme ve düzeltme yaptırılır (MEB, 2017b, s. 161).

39. Etkinlikte, öğrenciler gruplara ayrılır. Her grup kendi bulmacasını hazırlar. Hazırlanan bulmacalar karşılıklı olarak çözülür. Anlamını bilmedikleri kelimeler ile ilgili sözlük çalışması yapmaları hatırlatılır. İkinci aşamada ortaya çıkan kelimeler kullanılarak bilgilendirici bir metin yazilır (MEB, 2017b, s. 312).

Öğrencilerin yazma çalışmalarında bireysel çalışmalarına imkân tanıyan etkinliklerin yanında grupla çalışmalarına yönelik etkinliklere de yer verilmiştir. Öğrenciler yazdıkları metinleri isterlerse grup sözcüsüne okutabilmekte, grupla yazılarını canlandırabilmekte ve grupla birlikte değerlendirebilmektedirler (MEB, 2017b, s. 144, 150, 161, 289, 312).

Bu boyutta öğretim programının içeriğinin öğretilme yolları, öğrencilerin bilgiyi öğrenme, verilen bilgilerden hareketle o bilgiyi kullanabilme biçimlerini incelendiğinde ileri düşünme becerilerinin kullanıldığı, yaratıcı etkinliklere yer verildiği, öğretimin hızının bireyselleştirildiği, keşif yoluyla öğrenmenin olduğu, öğretim yollarının çeşitlendirildiği, değerlendirmede açık uçluluğa yer 
verildiği tespit edilmiştir. Bu yönleriyle Etkinliklerin hem Maker Modeline Göre Sürecin Farklılaştırılması Açısından hem de Bilim ve Sanat Merkezleri Yönergesine uygun olduğu anlaşılmıştır.

\section{Maker Modeline Göre Ürünün Farklılaştırılması Açısından Yazma Becerisi Etkinliklerinin Bilim} ve Sanat Merkezleri Yönergesiyle Uyumluluğu

Bilim ve Sanat Merkezleri Türkçe Etkinlik Kitabında değerlendirme bölümlerinde verilen ölçekler, etkinlik sürecine bağlı olarak değişiklik gösterebilmektedir. Bu ölçekler, öğrenme süreçlerini takip ederek öğrencinin gelişiminin izlenmesini sağlamaktadır (MEB, 2017b).

Türkçe Etkinlik Kitabındaki;

54. Etkinlikte, öğrencilerin kullandıkları iletişim araçlarını kullanım sıklıklarına göre sıralamaları istenir. Özellikle yazılı iletişim araçları ile ilgili sorular sorularak öğrencilerin bilgiye ulaşma amaçlı olarak kullandıkları yazılı iletişim araçlarına vurgu yapılır. Gazete incelemeleri yapılarak haber metinleri ile bir konuda yazarın güncel bir olayı kişisel olarak ele alıp yorumladığı metinleri (Fıkra) ayırt etmeleri istenir. Fıkra örnekleri incelettirilerek, türün genel özellikleri sezdirilir. Güncel olaylar ile ilgili beyin fırtınası yaptırılarak her öğrencinin bu olaylardan bir tanesini seçmesi sağlanır. Seçilen konuda kısa bir fıkra metni (yaş ve seviyeye bağlı olarak öğrenciye rehberlik edilmesi çok önemlidir) yazmaları istenir. Sınıf panosunda bir köşe oluşturulur. Yazılan metinler birlikte değerlendirilerek sınıf panosuna asılır. Öğrencilere panodaki yazıların her hafta yenileriyle değiştirileceği söylenerek yazma alışkanlığı kazanmalarına destek olunur. Öğrenciler, bilgilendirici metin yazarları ve eserleri ile ilgili araştırma yapmaya yönlendirilir. Elde ettikleri verileri düzenleyerek bilgilendirici metin oluşturmaları ve bu metinleri arkadaşları ile paylaşmaları istenebilir (MEB, 2017b, s. 168).

40. Etkinlikte, öğretmen, derse öğrencilere son zamanlarda çevrelerinde dikkatlerini çeken, onlara ilginç gelen, üzen, sevindiren, şaşırtan bir olaya şahit olup olmadıklarını sorarak başlar. Sorucevap yöntemiyle anlatılan olaylarda öğrencilerin nelerden etkilendikleri anlaşılmaya çalışılır. Ardından öğrencilerden anlattıkları olaylardaki kişiler, yer, zaman ya da olayın aşamaları gibi unsurları değiştirerek olayı öyküleştirmeleri istenir. Öğretmen, gündelik bir olayın edebîleştirilerek söz sanatlarını, anlatım biçimlerini vb. kullanarak öyküye dökülmesini ister, bunun için öğrencilere bir ders saati süre verileceğini belirtir (MEB, 2017b, s. 315).

Bilim ve Sanat Merkezlerindeki yazma çalışmalarında üründe de farklılaştırmaya gidilmektedir ve öğrencilerin istedikleri türlerde yazma çalışmaları yapmalarına olanak sağlanmaktadır. Etkinlik kitabında gerçek dünya sorunlarını ele alan yazma çalışmaları yer almaktadır ve bu yazma çalışmalarında yazılı iletişim araçları, güncel olaylar yazma konusu seçilmektedir (MEB, 2017b, s. 166, 168, 291, 315). 
43. Etkinlikte, öğrencilere bir masal dinlettirilir. Masaldaki gerçek dışı unsurları bulmaları istenir. Masalı masal yapan unsurları sezmeleri sağlanır. Tekerleme, kişiler, zaman, mekân ve olay örgüsünü örnek masallar üzerinden fark etmeleri sağlanır. Tüm bu unsurlar ve masal içindeki özelliklerinin ne olması gerektiği anlatılır. Masal ile ilgili olarak 5N1K soruları sorup cevaplamaları sağlanır. Kendi masallarını yazmak için ihtiyaç duyacakları bilgilere 5N1K soruları ile ulaşmaları, olay örgüsünü ve zıtlıkları planlamaları sağlanır. İhtiyaç duydukları durumlarda rehberlik edilerek masallarını oluşturmaları için pekiştirmeler yapılır. Yazdığı masalı kitapçık formatında düzenler. Masalın görsellerini yapmaları istenebilir (MEB, 2017b, s. 142).

48. Etkinlikte, Keloğlan Masallarından örnekler ile tekerlemelere dikkat çekilir. Geleneksel Türk masallarının başında, ortasında ve sonundaki tekerlemelerin (formellerin) farkına vardırılır. Tekerlemelerin masala ne kattığı kattığı sorgulatılır. Masalı diğer türlerden ayıran özellikler beyin fırtınası ile sıralattırılır. Keloğlan Masallarındaki karakterler öğrencilere tespit ettirilerek karakterlerin kişilik ve fiziksel özellikleri gruplandırılır. Keloğlan'ı diğer masal karakterlerinden ayıran özellikler tespit edilir. Öğrencilerden, içinde formeller olan özgün bir Keloğlan masalı yazmaları istenir (MEB, 2017b, s. 152).

Öğrencilerin yaratıcılık özelliklerini ortaya çıkartmak için de yaratıcı yazma tekniğine başvurulduğu tespit edilmiştir (MEB, 2017b, s. 142, 146, 152, 287, 289, 299). Ayrıca geleneksel ödev mantığının dışında farklı şekillerde ürünlerini ortaya koymalarını sağlayan sunum imkânları tespit edilmiştir ve bu sunumlar ürünlerin çeşitlenmesine de yol açmıştır (MEB, 2017b, s. 166, 168, 289, 308). Öğrencilerin seçtikleri türdeki metinler için de farklılaştırılmış ölçme araçlarına ihtiyaç duyulmaktadır. Bu sayede değerlendirme süreci de öğrenci ürünlerindeki çeşitliliğe bağlı olarak farklılaşmaktadır.

Ürünün farklılaştırılmasında öğrencilerden beklenen davranışlarda içerik ve süreç boyutundaki farklılaştırmalara bağlı olarak ürünün sunuluş biçiminde, ürün ortaya koymada, çeşitli yöntem ve tekniklerden faydalanıldığı, ürün tasarımlarında öğrenci merkezli olduğu, hedef kitlenin belirlenmesinde öğrencilerin görüşlerinin etkili olduğu tespit edilmiştir ve bu yönlerinin Bilim ve Sanat Merkezleri Yönergesiyle de uyumlu olduğu anlaşılmıştır.

4. Maker Modeline Göre Öğrenme Ortamının Farklılaştırılması Açısından Yazma Becerisi Etkinliklerinin Bilim ve Sanat Merkezleri Yönergesiyle Uyumluluğu

Bilim ve Sanat Merkezlerinde öğrencilerin gelişimlerini desteklemek amacıyla atölyeler oluşturulmaktadır. Destek eğitim programı uygulama sürecinde zenginleştirme, farklılaştırma ve hızlandırmanın sağlanabilmesi için tema/atölye temelli etkinlikler uygulanabilmektedir (MEB, 2015). $\mathrm{Bu}$ atölyelerde öğrencilerin ilgileri, öğrenme alanları ve ilgilerine uygun destekleyici ortamlar düzenlenmektedir. $\mathrm{Bu}$ atölyelerde uygulanmak üzere belli programlar hazırlanmaktadır. Eğitim 
programları hazırlanırken de üst bilişsel düşünme becerilerini geliştirmesini sağlayan etkinliklerin planlanmasına ve uygulamasına dikkat edilmektedir (MEB, 2015). Öğrenme ortamında farklılaştırma yoluyla destekleyici ve öğrenci merkezli anlayış hâkimdir. Yazma etkinliklerinde bilişim teknolojilerinden faydalanılmaktadır. Web 2.0 araçları ve sunum programlarının kullanıldığı tespit edilmiştir (MEB, 2017b, s. 146, 300). Öğrenciler öğrenme ortamına gelmeden de yazma becerilerini teşvik edici ortamın hazırlanması gerektiği etkinlik kitabında belirtilmiştir (MEB, 2017b, s. 153, 291).

Öğrenme ortamının farklılaştırılmasında öğrenci merkezli olması gerektiği, ideal öğrenme fırsatlarının oluşturulduğu, aktif katılıma imkân tanındığı, mentörlük faaliyetlerine uygun olduğu, bireysel tercihlere olanak tanıdığı anlaşılmıştır. Bu yönleriyle de yazma becerilerinin ilgili yönerge ile de uyumlu olduğu anlaşılmıştır.

\section{Tartışma}

Türkiye'de okul öncesi, ilkokul, ortaokul ve lise düzeylerinin öğretim programlarının içeriği ve ölçme değerlendirmesi ulusal standartlara göre belirlenmektedir. Bu durumda öğretim ortamının ve sürecinin her öğrenciye aynı verinin ve yöntemin uygulanacağı anlaşılmaktadır; fakat bu verilen genel çerçevenin içeriğinin farklılaştırılması öğretmene bırakılmıştır. Ancak okul öncesi, ilkokul, ortaokul ve lise düzeylerinde ders materyallerinin içeriğinde farklılaştırma stratejisine uygun yeterince örnekler yer almamaktadır. Bu eğitim düzeylerinde içerikle, öğrenme yaşantısıyla ve ürünle ilgili öğrencilerin ön bilgilerinin ve hazır bulunuşluklarının dikkate alındığına dair herhangi bir bölüm de tespit edilmemiştir.

Farklılaştırılmış eğitimi uygulayabilmek için de öğrencilerin belli özelliklere göre gruplandırılması gerekmektedir; fakat örgün eğitim sistemi içerisinde öğrencilerin belli özelliklere göre gruplandırarak ve farklılaştırılmış eğitim uygulama imkânı mümkün görülmemektedir.

Tespit edilen etkinlikler, öğrencilerin farklılaştırılmasını destekleyecek sayıda mıdır, bu öğretim için yeterli midir? Ayrıca bu etkinlikler, kaç öğretmen tarafından ne kadar çeşitlendirilebilmektedir? Bu soruların cevabı mutlaka aranmalıdır.

İçeriğin farklılaştırılmasında yetenekli öğrenciler kadar donanımlı öğretmenlere de ihtiyaç vardır. Öğrencilere daha kapsamlı ve karmaşık düzeyde yazma çalışmaları mutlaka verilmelidir. Bu çalışmaların soyutluk derecesi artırılarak yazı kurgusu geliştirilebilmelidir. Bu sayede özel yetenekli öğrenciler yaşıtlarından farklı olarak kendilerini daha iyi ifade etmiş olacaktır. Bilim ve Sanat Merkezlerine devam eden öğrenciler görsel sanatlar, müzik ve genel zihinsel yetenek alanlarına göre gruplandırıldıkları için yazma çalışmalarını farklılaştırmak, temel eğitime devam eden öğrencilerde uygulanan yazma çalışmalarına göre daha da kolaylaşmaktadır. Bu yazma çalışmalarında tür eğitimi ve farklı seviyedeki türlerin öğrenci ilgilerine göre çalışma yapraklarında verilmesi de eğitimin başarısını artıracaktır. 
Öğrenme sürecini farklllaştırmada öğrenme etkinliklerinin çeşitlendirilmesi ve bu etkinliklerin hedeflenen kazanımlara ulaşmayı kolaylaştırıcı olması gerekmektedir. Bilim ve Sanat Merkezleri programları, öğrenci merkezli ve disiplinler arası yapıda hazırlanmaktadır. Programlar, lider ve/veya danışman öğretmenlerin rehberliğinde bireysel öğrenmeye uygun olarak hazırlanmaktadır (MEB, 2015). Bu sayede süreç içinde farklılaştırmada yazma çalışmalarında geride kalan öğrencilere desteği farklılaştırma, gruplama uygulamaları, daha hızlı öğrenenler ve yazanlar için hızı farklılaştırma gerekmektedir. Bu uygulamalar aracılığıyla da her bir öğrencinin bireysel öğrenme hızı dikkate alınmış olacaktır.

Ürünün farklılaştırılmasında ise hazır bulunuşlukları, ilgileri ve öğrenme profilleri farklı olan bireylerin standart yazı metinleri oluşturması beklenmemelidir. Ön bilgisi farklı öğrencilerin olduğu bir sınıfta herkesin standart bir ürün oluşturması beklenemez (MEB, 2017a). Bilim ve Sanat Merkezlerine devam eden öğrenciler yazma çalışmalarında ürün çıktısında farklılaştırılmaktadırlar. Farklılaştırılan ürünler için tür çalışmaları yapılmaktadır. Öğrencilerin öğrenme stilleri de grupla mı yoksa bireysel mi çalışacaklarını belirlemektedir. Ürünler de çeşitlendirilmiş yazma ölçekleriyle değerlendirilmektedir.

Normal sınıflarda da farklılaştırılmış eğitim kapsayıcı eğitim içerisinde yer almalıdır. Kapsayıcı sınıflarda öğretmenler tüm öğrencilere ulaşmayı ve tüm öğrencileri motive etmeyi amaçlar. Kapsayıcı eğitimi benimsemiş öğretmenler materyalleri, ders planlarını, öğretim stratejilerini, öğrenme ortamını, eğitsel hedefleri kapsayıcılık anlayışına göre düzenlemeyi ve öğrencilerin akademik ve sosyal ihtiyaçlarını karşılamayı amaçlar. Beyin araştırmaları (Howard, 1994; Jensen, 1998) öğrencilere, onları aşırı zorlayacak veya onlara çok kolay gelecek görevlerin değil onların seviyelerinde veya seviyelerinin çok az üstünde zorlukta olan görevler verildiğinde en iyi öğrenmelerin gerçekleştiğini ortaya çıkarmıştır. Vygotsky (1962, 1978), öğretmenin öğrenciye kapasitesinin biraz ötesinde bir işi tek başına yapma görevi verdiğinde öğrencinin öğrenmeye başladığını söyler. Bu şekilde düzenlenmiş öğrenme yaşantıları sayesinde, öğrencilerin potansiyelleri en iyi şekilde kullanılarak etkinliklerin verimliliği artırılmış olacaktır.

Bu çalışmada, Bilim ve Sanat Merkezlerinde kullanılan Türkçe Etkinlik Kitabında yer alan yazma çalışmalarının Maker Modeline göre süreç, ürün, içerik ve ortam açılarından farklılaştırma durumları ile uyumlu olduğu ve Türkçe Etkinlik Kitabında yer alan yazma çalışmalarının Bilim ve Sanat Merkezleri Yönergesiyle de uygunluk sağladığı tespit edilmiştir. Ancak bu çalışmada; tespit edilen etkinliklerin, öğrencilerin farklılaştırılmasını destekleyecek yeterli sayıda olmadığı görülmüştür. 


\section{Sonuç}

Müfredat modelleri ülkeden ülkeye hatta ülke içerisinde bile farklılık gösterebilmektedir. Bu kadar farklı müfredat modelinin olduğu bir dönemde en iyi müfredat modelinin şu veya bu olduğunu iddia etmek çok doğru olmayacaktır. Zaten hâli hazırda var olan modeller de bunu iddia etmemekte birbirini tamamlayacak niteliktedir.

Müfredat modellerinin tamamı öğrenme etkinliklerinin geliştirilmesine ve planlamasına temel oluşturan kuramsal çerçeveler sunarlar. Üstün zekâlı öğrencilerin eğitimlerinde yaygın olarak kullanılan müfredat modellerinin çoğu içerik, süreç, ürün ve öğrenme ortamı olmak üzere genel müfredatın dört ana boyutu üzerine yoğunlaşırlar ve bu boyutları üstün zekâlı öğrencilerin özelliklerine ve öğrenme gereksinimlerine göre farklılaştırma stratejileri sunarlar (Sak, 2017). Üstün zekâlı öğrencilerin eğitimlerinde içerik bilgilerinde derinlik ve karmaşıklık, gerçek yaşam sorunları ve bağımsız öğrenme ortamı farklılaştırmada temel alınır.

Üstün zekâlı öğrencilerin eğitimlerinde kullanılan müfredat modellerinden çıkarılan ilkeler şunlardır:

- Müfredat kapsamlı kavram, tema ve problemlerden oluşmalıdır.

- Disiplinlerarası konulara ve problemlere yer verilmelidir.

- Bağımsız araştırma becerileri geliştirilmelidir.

- Yaratıcı ve analitik düşünme gibi ileri düşünme becerileri geliştirilmelidir.

- Açı uçlu etkinlik ve problemlere ağırlık verilmelidir.

- Yeni fikir üretme, var olan fikirleri ise eleştirme teşvik edilmelidir.

- Öğrenci ürünlerinin değerlendirilmesinde kullanılan ölçütler standart ve yeterince spesifik olmalıdır.

- Öğrenci ürünlerinin geliştirilmesinde konu, biçim, yöntem ya da sunu türünü öğrenciler kendi tercihlerine göre seçmelidir (Sak, 2017).

$\mathrm{Bu}$ müfredat ögelerinin farklılaştırmasında dört tür uyarlama yapılır ve bunlar düzey, hız, karmaşıklık ve derinliktir. Maker Modelinin bu farklılaştırma ögeleri yazma becerileri açısından değerlendirildiğinde uygulanmasının uygun olduğu görülmektedir. Bu model haricinde de başka modeller de mevcuttur. Bu modeller ÜYEP Müfredat Modeli, Paralel Müfredat Modeli, Müfredat Daraltma Modeli, Entegre Müfredat Modeli, Izgara Müfredat Modeli ve Çoklu Menü Modelidir. Maker Modeli dışındaki modellerde yazma becerilerini kapsayacak bir tasarım oluşturmak oldukça güçtür. Araştırma bulgularından hareketle Maker Modeline göre hem Bilim ve Sanat Merkezleri Yönergesi hem de Türkçe Etkinlikleri kitabındaki yazma çalışmaları artırılmalı ve öğrenciler üzerinde uygulanarak onların geribildirimleri doğrultusunda düzenlenerek işlevselliği artırılmalıdır. 
Bu özel öğrencilere daha iyi ve etkili eğitim verebilmek için modeli uygulayacak öğretmenlere ve kitap hazırlayıcılara; modelle, Bilim ve Sanat Merkezleri Yönergesiyle ve ders programıyla, etkinlik hazırlama ile ilgili eğitimlerin verilmesi gerektiğini düşünmekteyiz. Çünkü bu etkinliklerin, kaç öğretmen tarafından ne kadar çeşitlendirilebildiği noktasında bazı tereddüt ve şüphelerimiz bulunmaktadır. Bu soruların cevabına yönelik akademik çalışmaların da yapılması gerektiği kanaatindeyiz.

\section{Kaynaklar}

Çavuşoğlu, M., \& Semerci, N. (2015). Anne babaların BíLSEM'e devam eden özel yetenekli çocuklarına ilişkin görüşleri (Bartın ili örneği). Bartın Üniversitesi Eğitim Fakültesi Dergisi, Mayıs, 325-335.

Demirçelik, E., Karacabey, A. S., \& Cenan, E. (2017). Özel yetenekli öğrencilerin liderlik becerilerinin bazı değişkenler açısından incelenmesi. Uluslararası Toplum Araştırmaları Dergisi, Aralık, 399425.

Howard, P. J. (1994). An owner's manual for the brain. Austin, TX: Leornian.

Jensen, E. (1998). Teaching with the brain in mind. Alexandria, VA: Association of Supervision and Curriculum Development.

Maker, C. J. (1982). Curriculum development for the gifted. Austin, TX: Pro-Ed.

MEB. (2015). Millî Eğitim Bakanlığı Bilim ve Sanat Merkezleri Yönergesi. http://orgm.meb.gov.tr/meb iys dosyalar/2015 09/18101802 bilimvesanatmerkezleriynergesi. pdf sayfasından erişilmiştir.

MEB. (2017a). Sınıfında Yabancı Uyruklu Öğrenci Bulunan Öğretmenler için El Kitabı. T. C. Millî Eğitim Bakanlığı Öğretmen Yetiştirme ve Geliştirme Genel Müdürlüğü, Ankara: MEB Yayınları.

MEB. (2017b). Bilim ve sanat merkezleri Türkçe etkinlik kitabı. MEB: Özel Eğitim ve Rehberlik Hizmetleri Genel Müdürlüğ̈̈. http://bilsem.meb.gov.tr/login.aspx sayfasından erişilmiştir.

Sak, U. (2017). Üstün zekâlılar. Ankara: Vize Basın Yayın.

Tomlinson, C. A. (2014). Öğrenci gereksinimlerine göre farklılaştırılmış eğitim. (T. Bayındır, Çev. Ed.). İstanbul: Redhouse Eğitim Kitapları.

Vygotsky, L. S. (1962). Thought and language. Cambridge, MA: MIT Press.

Vygotsky, L. S. (1978). Mind in society. Cambridge, MA: Harvard Universty Press.

Yıldırım, A., \& Şimşek, H. (2006). Sosyal bilimlerde nitel araştırma yöntemleri. Ankara: Seçkin Yayıncılık. 


\section{Extended Summary}

Students have different needs. Especially learning styles, learning areas, and attitudes of gifted students are known. For this reason, differentiated activities suitable for learning styles should be prepared in the course content for gifted students.

From the differentiated education process, we have understood the diversification of learning experiences applied to students with enriching activities. Enrichments are usually determined by student needs.

It is also necessary to include writing skills in differentiated learning experiences in the Turkish Language lesson; because giving a subject and asking the class to write about it in a certain type of writing will ignore the individual differences of the students.

Gifted students in Turkey, in addition to the planned formal education process, will continue their education in Science and Art Centres. Students participate in Science and Art Centres from visual abilities, music ability, and general mental skills. Because these students are classified according to their learning styles, there is a need for differentiation in the prepared in-class activities; in the content of the activity, in the process of the activity, and in the product output.

Activities to improve writing skills as language skills should be of a quality to cater to the students learning styles.

The aim of this study is to detect, in Turkey, how the writing studies prepared for gifted students are differentiated. For this, was compared the compatibility of the activity contents carried out in Science and Art Centres with the Science and Art Centres Directive.

For this purpose, firstly, in research methodology, we will give the conceptual framework of differentiation concepts in the Maker Model. Then will be included the method, findings, discussion, and conclusion sections determined in connection with Maker Model.

According to Maker (1982), curriculum elements should be differentiated quantitatively and qualitatively during the education of gifted students. This model includes four main dimension differentiations in general curriculum elements: content, process, product, and learning environment. These structures, in themselves, are divided into sub-dimensions: abstractness, complexity, diversity, organization, the life of the distinguished people; research methods, advanced thinking, openendedness, exploratory learning, reasoning, diversity, the speed of teaching; problems from real life, real audience, evaluation, synthesis, diversity; learner centered-teacher centered, acceptancejudgement, variable grouping-similar grouping, independence-dependency, complexity-simplicity, openness-closeness. 
In this study, we used a qualitative research method. Research data were gathered through document analysis which is one of the qualitative research methods. Document analysis makes it possible to analyze documents produced in a specific time period about a research problem or documents produced by multiple sources and at different intervals based on a wide timeframe and can be used as a data source in document analysis in a research related to education (Yıldırım \& Şimşek, 2008). This method was preferred because the research aim was to collect differentiated writing activities.

Five stages were followed in this research, where document analysis was conducted: access to documents, control of documents, understanding the documents, analyzing the data, and the use of data obtained for the purpose of the study.

The study group of the research consisted of writing skills activities in the Activity Textbook in Turkish Language used in Science and Art Centres and the Directive of the Ministry of National Education Sciences and Art Centres.

For the purpose of this study, we used the writing skills activities in Science and Art Centres, the Turkish Education Programs of Science and Art Centres, and the Directives of Sciences and Art Centres.

Curriculum models may differ from country to country, even within the country.

All curriculum models offer theoretical frameworks that underpin the development and planning of learning activities.

Most of the curriculum models commonly used in the education of gifted students focus on the four main dimensions of the general curriculum, including content, process, product, and learning environment, and these dimensions offer strategies to differentiate according to the characteristics and learning needs of gifted students (Sak, 2017).

The principles drawn from the curriculum models used in the education of gifted students are:

- The curriculum should consist of comprehensive concepts, themes, and problems.

- Interdisciplinary topics and problems should be included.

- It needs to develop independent research skills.

- Advanced thinking skills such as creative and analytical thinking should be developed.

- Open-ended activities and problems should be emphasized.

- It should be encouraging for creating new ideas and criticizing existing ideas.

- The criteria used to evaluate student products should be standard and sufficiently specific. 
- In the development of student products, students should choose the type of subject, form, method, or presentation according to their preferences (Sak, 2017).

There are four types for adapting the differentiation curriculum elements: level, speed, complexity, and depth. It is known that Maker Model is appropriate to apply when these differentiation elements are evaluated in terms of writing skills. Except for this model, there are other models. These models are Education Programs for Talented Students (EPTS) Curriculum Model, Parallel Curriculum Model, Curriculum Collapse Model, integrated Curriculum Model, The Grid Model, and Multiple Menu Model. It is difficult to create a design that covers writing skills as the Maker Model.

Based on the research findings, according to the Maker Model Directive of the Science and Art Centres and the Activity Textbook in Turkish Language provide compatibility.

In Turkey, the same data and methods are applied to all students in the educational environment and process. However, the differentiation of the given content of this general framework is left to the teacher. But there aren't enough examples in the content of the course materials in preschool, primary, secondary, and high school levels suitable for the differentiation strategy. No section has been identified in these educational levels regarding the prior knowledge and readiness of students about the learning experiences, and the product is taken into consideration.

To implement differentiated education, students must be grouped according to certain characteristics, but in the formal education system, it isn't possible to group students according to certain characteristics and to implement differentiated education.

In differentiated content, more comprehensive and complex writing activities should be given to talented students.

Writing fiction should be improved by increasing the degree of abstraction of these studies. In this way, gifted students will express themselves better than their peers. Since students attending Science and Art Centres are grouped according to visual arts, music, and general mental talent fields, differentiating their writing activities becomes easier than the writing activities applied in students attending basic education. In these writing activities, species education and giving different types of species in worksheets according to student interests will increase the success of education.

In differentiating the learning process, learning activities should be diversified, and they shouldfacilitate reaching the targeted achievements. The programs of Science and Art Centres are prepared in a student-centered and interdisciplinary structure. Programs are prepared in accordance with individual learning under the guidance of leading and/or counseling teachers (MNE, 2015). In this way, it is necessary to differentiate support for students who are left behind in the process of writing in differentiation, grouping practices, speed differentiation for those who learn and write fast. 
Through these applications, the individual learning speed of each student will be taken into consideration.

In the differentiation of the product from individuals with different readiness, interests, and learning profiles, it shouldn't be expected to create standard texts. In a classroom with different prior knowledge, we can't expect everyone to create a standard product (MNE, 2017a).

Differentiated education should also be included in inclusive education in normal classes. In inclusive classes, teachers aim to reach all students and motivate all students. Teachers who have embraced inclusive education aim to organize the materials, lesson plans, teaching strategies, learning environment, educational goals according to the comprehension of inclusion and to meet the academic and social needs of students. Brain research (Howard, 1994; Jensen, 1998) has revealed that students are given the best learning when they are given tasks that are overly or slightly above their level and not tasks that will overwhelm them or make them easier. Vygotsky $(1962,1978)$ says that the student starts learning when the teacher gives the student tasks beyond her/his capacity. Regarding the learning experiences organized in this way, by using the potentials of the students in the best way, the efficiency of the activities will be increased.

\section{Araştırmacıların Katkı Oranı Beyanı}

Bu araştırmaya birinci yazar \% 50, ikinci yazar \% 50 oranında katkıda bulunmuştur.

\section{Destek ve Teşekkür Beyanı}

Bu araştırmada herhangi bir kurum, kuruluş ya da kişiden destek alınmamıştır.

\section{Çatışma Beyanı}

Araştırmacıların araştırma ile ilgili diğer kişi ve kurumlarla herhangi bir kişisel ve finansal çıkar çatışması yoktur.

\section{Etik Kurul Beyanı}

$\mathrm{Bu}$ araştırma doküman incelemesi yapılarak yürütüldüğünden etik kurul kararı gerektirmemektedir. 